Structural Eng. / Earthquake Eng. Vol.4. No.1, 209s-215s. April 1987

Japan Society of Civil Engineers (Proc. of JSCE No.380/I-7)

\title{
MEASUREMENT OF THE JMA MAGNITUDE WITH SLIP DISPLACEMENT
}

\author{
By Shunichi IGARASHI* and Motohiko HAKUNO**
}

\begin{abstract}
A method is presented to measure the magnitude of earthquakes from the slip displacement of the friction-controlled SDOF system. A statistical relation among JMA magnitude, slip displacement, focal distance, and the critical acceleration of the system is obtained with 52 sets of strong motion accelerograms in Japan. This relation is then used as a measurement equation of the magnitude of earthquakes from slip displacement. The estimated magnitudes at various sites are found to be consistent within each earthquake with an averaged standard deviation of 0.10 . The proposed method can be used to measure the magnitude of earthqrakes from various sources such as slip displacement measured in a block on an inclined plane, earth dams, slopes, and other structures.

Keywords: magnitude, slip displacement, measurement, SDOF system., earthquakes
\end{abstract}

\section{INTRODUCTION}

Important characteristics of ground motions, e. g. peak values, are related statistically to the magnitude of earthquakes. Several magnitude scales are commonly used such as local magnitude $M_{L}$, JMA magnitude $M_{J M A}$, and the surface wave magnitude $M_{s}$. The local magnitude $M_{L}$ has been defined from the peak trace of the standard Wood-Anderson torsional seismograph with $0.8 \mathrm{sec}$ natural period and 0.8 damping constant stationed $100 \mathrm{~km}$ apart from the epicenter (Richter 1935). Usually, the local magnitude is determined by averaging the values computed from the Wood-Anderson records of stations at various epicentral distances using the amplitude attenuation function proposed by Richter (1958).

When Wood-Anderson records are not available around $100 \mathrm{~km}$ from the epicenter, the determination of the local magnitude becomes a controversial issue. The magnitude of the 1940 Imperial Valley earthquake that produced the popular El Centro accelerogram was revised from the original 6.7 (Gutenberg and Richter 1949) to 7.1 (Richter 1958). This value is routinely used in engineering practices as a local magnitude, however, it is a surface-wave magnitude (Kanamori and Jennings 1978).

Kanamori and Jennings (1978) have addressed this issue and introduced a good method to estimate the local magnitude from accelerograms. They have synthesized the trace of the Wood-Anderson seismograph with accelerograms in the Caltech file (Caltech 1972) and computed their estimation of local magnitude for several earthquakes in the Western United States. They proposed $M_{L}=7.2$ for the 1952 Kern County earthquake based on their computation. This value was significantly smaller than the 7.7 determined by Gutenberg (1955). Their revision of the largest earthquake in the Western United States has been accepted by many researchers (Boore et al. 1980).

* Member of JSCE, M.S. in Civil Eng., TAISEI CORP. (Shinjuku, Tokyo)

** Member of JSCE, Dr. Eng., Prof. of Civil Eng., Univ. of Tokyo (Bunkyoku, Tokyo) 
The JMA magnitudes have been reported by the Japan Meteorological Agency for Japanese earthquakes and used routinely in engineering applications in Japan. They are computed based on the Tsuboi's formula (1954) that is a statistical relation among the peak ground displacement, epicentral distance and the local magnitude. The ground displacement may be a good indicator for the response of the Wood-Anderson seismograph in some class of earthquakes and site conditions, however, Tsuboi's formula and the JMA magnitude can be regarded as another definition of the earthquake magnitude based on the peak ground displacement.

In this paper will be presented a method to determine the magnitude of earthquakes based on the slip displacement that is the response of a friction-controlled single-degree-of-freedom system. The slip displacement has been found to be proportional to the total energy of the ground motion, therefore, it gives a consistent estimate of

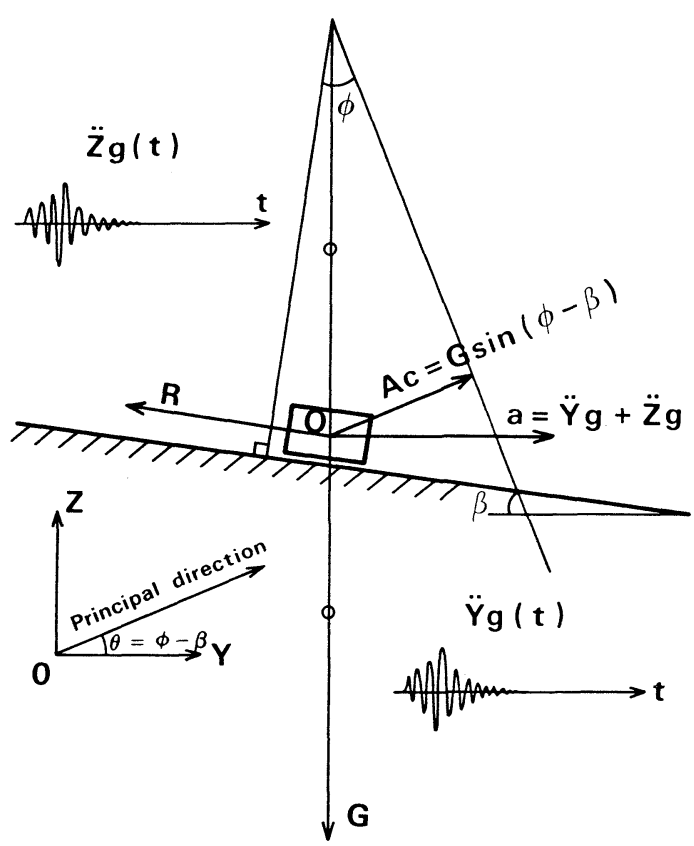

Fig. 1 Configuration of the friction-controled SDOF system. the magnitude of an earthquake at various stations.

\section{FRICTION-CONTROLLED SDOF SYSTEM}

Fig. 1 shows the configuration of the friction-controlled SDOF system. This system has been called mass-on-rough-plane model and used as an index of the earthquake resistant design of earth dams (Newmark 1965, Sarma 1975, Seed 1979), retaining walls (Richards and Elms 1979, Whitman and Liao 1985) and structures that allow sliding (Igarashi, Kajizuka and Hakuno 1985).

The input to this system is the movement of the rough plane $\left(\ddot{Y}_{g}(t), \ddot{Z}_{g}(t)\right)$ that is measured by a stationary coordinate system $Z O Y$ in Fig. $1 . \ddot{Y}_{g}(t)$ and $\ddot{Z}_{g}(t)$ is either of the horizontal components and the vertical component of the ground acceleration, respectively. The only internal force of this system is the Coulomb friction $R$ with friction angle $\phi$. The critical acceleration of the system

$A_{c}=G \sin (\phi-\beta)$

is the smallest of the magnitude of input that mobilizes the limit resistance against sliding, where $G$ is the gravity acceleration and $\beta$ is the inclination of the rough plane. The slip displacement is computed as the relative displacement of the mass to a reference point on the plane. In what follows slip displacement $S$ $(\mathrm{cm})$ will be measured in the principal direction that inclines $\theta=\phi-\beta$ from the horizontal (Fig. 1).

The behavior of this non-linear system to random excitation has been studied both analytically and empirically. The empirical mean slip displacement $S(\mathrm{~cm})$ has been obtained from a regression analysis against characteristics of ground motion with 140 accelerograms of the Western United States (Igarashi, 1986).

$$
S=0.214 s_{0}^{1.122} \sigma_{2}^{2.045} A_{c}^{-1.350} \omega_{c}^{-1.118} \exp \left(-0.886\left(A_{c} / \sigma_{2}\right)^{2}\right) F^{0.424}
$$

where $s_{0}(\mathrm{sec}), \sigma_{2}\left(\mathrm{~cm} / \mathrm{sec}^{2}\right)$ and $\omega_{c}(\mathrm{rad} / \mathrm{sec})$ is the strong motion duration, R. M. S. amplitude and central frequency of the ground acceleration, respectively. $F$ is a function of the bandwidth index $\alpha_{1}$ of the ground velocity,

$$
F=1+\frac{\pi}{2} \frac{\left(1-\alpha_{1}^{2}\right)^{1 / 2}}{\alpha_{1}}
$$


$s_{0}, \sigma_{2}, \omega_{c}$ and $\alpha_{1}=\lambda_{0} /\left(\lambda_{-2} \lambda_{2}\right)^{1 / 2}$ are computed from the $i$ 'th initial moment $\lambda_{i}$ of the power spectral density function $S(\omega)$ of the ground acceleration,

$$
\lambda_{i}=\int_{-\infty}^{\infty} \omega^{i} S(\omega) d \omega
$$

Another empirical mean slip displacement was obtained with 52 accelerograms recorded in Japan (Igarashi and Hakuno 1987)

$$
S=1.239 s_{0}^{0.999} \sigma_{2}^{2.237} A_{c}^{-1.356} \omega_{c}^{-1.447} \exp \left(-0.792\left(A_{c} / \sigma_{2}\right)^{2}\right) F^{0.535}
$$

The standard error of the estimate of Eqs. 2 and 5 is 0.553 and 0.441 , respectively in the natural $\log$ scale.

The analytical mean slip displacement has been computed for a stationary Gaussian excitation with duration $s_{0}$, standard deviation $\sigma_{2}$, central frequency $\omega_{c}$ and the bandwidth parameter $F$ (see Eq. 3) given the critical acceleration $A_{c}$ (Igarashi, 1986),

$$
S=\frac{s_{0} \sigma_{2}^{2}}{2 \pi \omega_{c} A_{c}} F \exp \left(-\frac{1}{2}\left(\frac{A_{c}}{\sigma_{2}}\right)^{2}\right)
$$

The exponential terms $\left(\right.$ e.g. $\left.\exp \left(-\frac{1}{2}\left(\frac{A_{c}}{\sigma_{2}}\right)^{2}\right)\right)$ in Eqs. 2, 5 and 6 are almost equal to unity for relatively small $A_{c} / \sigma_{2}$ that produce large slip displacement. From Eqs. 2, 5 and 6, slip displacement is found to be proportional to the total energy $I=\sigma_{2}^{2} S_{0}$ of the ground acceleration.

\section{MEASUREMENT OF THE MAGNITUDE WITH SLIP DISPLACEMENT}

\section{(1) Wood-Anderson seismograph}

The local magnitude is based on the seismic response of the standard Wood-Anderson seismograph that can be regarded as a linear system with 0.8 natural period, 0.8 damping coefficient. The amplitude response function of the Wood-Anderson seismograph can be computed from the SDOF equation of motion (Okamoto 1971),

$$
H\left(T_{g}\right)=\frac{x}{y_{0}}=\frac{1}{\left\{\left(1-\left(\frac{T_{g}}{0.8}\right)^{2}\right)^{2}+\left(2 \times 0.8 \frac{T_{g}}{0.8}\right)^{2}\right\}^{1 / 2}}
$$

in which $x$ and $y_{0}$ is the amplitude of the trace of the seismograph and the ground displacement with period $T_{g}$ respectively. In Fig. 2 is plotted the response function. The amplitude response function for the ground velocity $v$ is (Okamoto 1971),

$$
\frac{x}{v}=\frac{T_{g}}{2 \pi} H\left(T_{g}\right)
$$

The order of the ground velocity is,

$$
v \infty \frac{2 \pi}{T_{g}} y_{0}
$$

From Eqs. 7 through 9, the trace of the Wood-Anderson seismograph $x$ can be related either to ground displacement $y_{0}$ or velocity $v$,

$$
\begin{aligned}
& x \operatorname{cs} H\left(T_{g}\right) y_{0} \cdots \\
& x \cos T_{g} H\left(T_{g}\right) v
\end{aligned}
$$

Similar relation holds for the ground acceleration as well. The actual trace of the Wood-Anderson seismograph may be interpreted as a mixture of ground displacement, velocity, and acceleration due to the phase differences. Kanamori and Jennings (1978) have computed synthesized responses of the Wood-Anderson seismograph from accelerograms and reported that they looked like ground velocity rather than ground displacement. The response of the Wood-Anderson seismograph can be characterized with the monotonous shape of the response function (Fig. 2) that is convenient to measure a global quantity of ground motions without amplifying a particular component.

(2) Another SDOF system to measure magnitude 
The friction-controlled SDOF system in Fig. 1 can be compared with the linear SDOF system for its simplicity and importance in engineering applications. It is the basis of the sliding block analysis (Seed 1979) that is an important element of the earthquake resistant design of earth dams, retaining walls and other structures whose resistance to lateral force is mostly of a frictional nature. The mass-on-rough-plane model has a peculiar response characteristics, i.e., the slip displacement is proportional to the total energy of the input. This is also convenient to measure a global quantity of seismic waves.

The procedure to measure the magnitude of earthquakes with slip displacement of the frictioncontrolled system can be constructed in the following steps :

1) Compute slip displacements with accelerograms by integrating twice the relative acceleration of the mass to the rough plane (Fig. 1).

2) Obtain a regression equation that explains the magnitude $M_{A}$ of earthquakes by slip displacement, epicentral distance and the critical acceleration.

3) Use the regression equation as the formula to give the magnitude $M_{B}$ of earthquakes by the observed slip displacement.

When slip displacement, $M_{A}$ and $M_{B}$ is read peak ground displacement, local magnitude and JMA magnitude, respectively and when the regression analysis is conducted in the same data set as Tsuboi (1954), these steps would give the Tsuboi's formula.

\section{(3) Measurement equation}

78 components of strong motion records observed

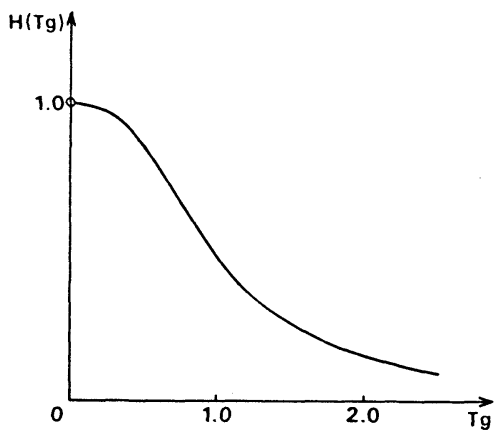

Fig. 2 Amplitude response function of the wood-anderson seismograph.

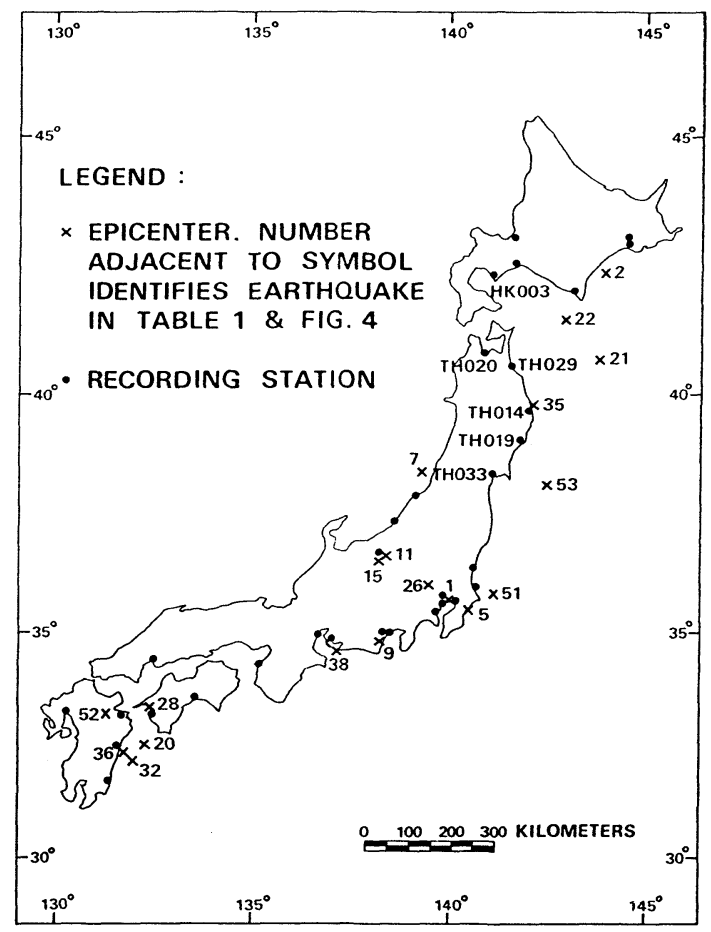

Fig. 3 Epicenters and recording stations of the 20 earthquakes. throughout Japan were selected from the NOAA file (NOAA 1981). In Fig. 3 are plotted the epicenters and the recording stations of the selected accelerograms. A total of 1040 slip displacements are computed for each pair of the vertical component and either of the horizontal components for various critical accelerations. The JMA Magnitude is explained by the focal distance $R(\mathrm{~km})$ critical acceleration $A_{c}$ $\left(\mathrm{cm} / \mathrm{sec}^{2}\right)$, and slip displacement $S(\mathrm{~cm})$ that is greater than $1 \mathrm{~cm}\left(\log _{10} S>0\right)$,

$$
M=2.39+0.470 \log _{10} S+0.843 \log _{10} A_{c}+1.481 \log _{10} R
$$

The standard error of estimate is 0.103 and the coefficient of determination is 0.866 . In Fig. 4 are plotted the JMA magnitudes computed by Eq. 11 against actual JMA magnitudes, where the numbers correspond to the earthquake ID on the map (Fig. 3). In Table 1 are listed JMAmagnitudes calculated by Eq. 11 for 1968 Tokachioki earthquake and other events. In the last but two columns of Table 1 are the mean values of the estimated JMA magnitude that are computed with Eq.11 for each of the slip displacement and critical acceleration. Next column is the standard deviation of the estimated value within 
Table 1 Estimated JMA magnitudes.

\begin{tabular}{|c|c|c|c|c|c|c|c|c|c|c|}
\hline \multirow{2}{*}{$\frac{\text { DATE }}{\text { JMA MAG. }}$} & \multirow{2}{*}{$\begin{array}{c}\text { STATION } \\
\text { NO. }\end{array}$} & \multirow{2}{*}{$\begin{array}{l}\text { FOCAL } \\
\text { DIST. } \\
(\mathrm{km})\end{array}$} & \multirow{2}{*}{$\begin{array}{c}\text { LOCAL } \\
\text { SOIL } \\
\text { CLASS* }\end{array}$} & \multirow[t]{2}{*}{ COMP. } & \multirow{2}{*}{$\begin{array}{c}\text { PEAK } \\
\text { ACC. } \\
\left(\mathrm{cm}^{2} / \mathrm{sec}\right)\end{array}$} & \multirow{2}{*}{$\begin{array}{c}\text { PEAK } \\
\text { VEL. } \\
(\mathrm{cm} / \mathrm{sec})\end{array}$} & \multirow{2}{*}{$\begin{array}{l}\text { PEAK } \\
\text { DISP. } \\
\text { (cm) }\end{array}$} & \multicolumn{3}{|c|}{ ESTIMATED MAG. } \\
\hline & & & & & & & & MEAN & S.D. & \\
\hline \multirow{4}{*}{$\begin{array}{l}5 / 16 / 1968 \\
M=7.9 \\
I D=21\end{array}$} & HK003 & 291 & 2 & $\begin{array}{l}\text { NS } \\
\text { EW }\end{array}$ & $\begin{array}{l}221.5 \\
155.3\end{array}$ & $\begin{array}{l}33.4 \\
15.9\end{array}$ & $\begin{array}{r}10.1 \\
6.6\end{array}$ & $\begin{array}{l}7.959 \\
7.914\end{array}$ & $\begin{array}{l}0.087 \\
0.074\end{array}$ & \multirow{4}{*}{$\begin{array}{l}M=7.83 \\
\text { S.D. }=0.09\end{array}$} \\
\hline & TH014 & 188 & 1 & NS & 164.9 & 6.1 & 0.8 & 7.548 & 0.102 & \\
\hline & TH020 & 243 & 3 & $\begin{array}{l}\text { NS } \\
\text { EW }\end{array}$ & $\begin{array}{l}227.3 \\
196.5\end{array}$ & $\begin{array}{l}39.7 \\
32.7\end{array}$ & $\begin{array}{l}19.4 \\
23.8\end{array}$ & $\begin{array}{l}8.136 \\
8.051\end{array}$ & $\begin{array}{l}0.092 \\
0.124\end{array}$ & \\
\hline & TH029 & 188 & 3 & $\begin{array}{l}\text { NS } \\
\text { EW }\end{array}$ & $\begin{array}{l}311.7 \\
206.2\end{array}$ & $\begin{array}{l}35.7 \\
40.5\end{array}$ & $\begin{array}{l}11.9 \\
20.6\end{array}$ & $\begin{array}{l}7.724 \\
7.837\end{array}$ & $\begin{array}{l}0.089 \\
0.070\end{array}$ & \\
\hline \multirow{2}{*}{$\begin{array}{l}4 / 5 / 1966 \\
M=5.4 \\
I D=11\end{array}$} & (2) & 5.6 & 4 & $\begin{array}{l}\text { NS } \\
\text { EW }\end{array}$ & $\begin{array}{l}265 \\
499\end{array}$ & $\begin{array}{l}11.1 \\
21.4\end{array}$ & $\begin{array}{l}1.0 \\
2.5\end{array}$ & $\begin{array}{l}5.050 \\
5.325\end{array}$ & $\begin{array}{l}0.095 \\
0.066\end{array}$ & \multirow{2}{*}{$\begin{array}{l}M=5.22 \\
\text { S.D. }=0.09\end{array}$} \\
\hline & (3) & 5.0 & 3 & $\begin{array}{l}\text { NS } \\
\text { EW }\end{array}$ & $\begin{array}{l}259 \\
268\end{array}$ & $\begin{array}{l}20.3 \\
17.3\end{array}$ & $\begin{array}{l}2.9 \\
1.8\end{array}$ & $\begin{array}{l}5.298 \\
5.212\end{array}$ & $\begin{array}{l}0.107 \\
0.105\end{array}$ & \\
\hline \multirow{2}{*}{$\begin{array}{l}6 / 12 / 1978 \\
M=7.4 \\
I D=53\end{array}$} & TH019 & 122 & 1 & $\begin{array}{l}\text { N41E } \\
\text { E41S }\end{array}$ & $\begin{array}{l}206.7 \\
222.1\end{array}$ & $\begin{array}{l}12.8 \\
14.1\end{array}$ & $\begin{array}{l}2.2 \\
5.1\end{array}$ & $\begin{array}{l}7.081 \\
7.170\end{array}$ & $\begin{array}{l}0.053 \\
0.050\end{array}$ & \multirow{2}{*}{$\begin{array}{l}M=7.41 \\
\text { S.D. }=0.07\end{array}$} \\
\hline & тн033 & 126 & 3 & $\begin{array}{l}\text { NS } \\
\text { EW }\end{array}$ & $\begin{array}{l}314.3 \\
288.2\end{array}$ & $\begin{array}{l}28.6 \\
52.9\end{array}$ & $\begin{array}{r}6.5 \\
10.7\end{array}$ & $\begin{array}{l}7.622 \\
7.770\end{array}$ & $\begin{array}{l}0.107 \\
0.075\end{array}$ & \\
\hline
\end{tabular}

* NOTE According to the JSCE Classification

each record. In the last column are listed the overall mean values of the estimated magnitude for the earthquake. These values can be compared in a good agreement with the JMA magnitudes in the first column.

The standard deviations of the estimated magnitude are very low and it implies that one can choose the critical acceleration of the model freely as long as it produces slip displacement more than $1 \mathrm{~cm}$. The following procedure to measure the magnitude of earthquakes is proposed:

1) Obtain slip displacements of ground motions by either processing accelerograms with the friction-controlled SDOF system for various critical accelerations (e.g, $A_{c}=0.05 A$, $0.1 A, 0.15 A, \cdots$, A being the peak accelera-

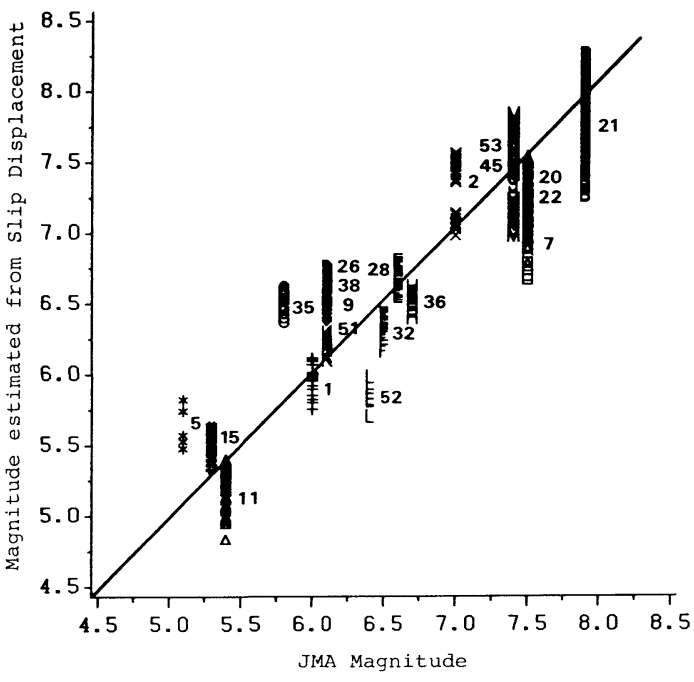

Fig. 4 Estimated magnitudes against JMA magnitudes. tion) or by measuring the movement of a block on a rough plane whose critical acceleration is known.

2) Use Eq. 11 or equivalent statistical equation and compute the magnitude from the slip displacement, critical acceleration and the focal distance.

3) Average the values computed from above and attain the estimated magnitude of the earthquake.

\section{DISCUSSIONS}

The slip displacement of the friction-controlled SDOF system has found to give a consistent estimate of the JMA magnitude. The proposed measurement equation was obtained in a similar procedure to the derivation of the Tsuboi's formula. The regression coefficient may change as one uses different data set, however, this is also the case with Tsuboi's formula. A regression equation of the JMA magnitude $M$ 
against the peak ground displacement $D$ (microns) and the focal distance was obtained for our data set, $M=0.76+0.785 \log _{10} D+1.359 \log _{10} R$.

The standard error of estimate is 0.14 and the coefficient of determination is 0.832 . Eq. 12 can be compared with the regression equations obtained by Tsuboi (1954),

$$
\begin{aligned}
& M=1.36+0.65 \log _{10} D+1.30 \log _{10} \Delta \\
& M=1.11+0.78 \log _{10} D+1.27 \log _{10} \Delta \\
& M=-0.83+\log _{10} D+1.73 \log _{10} \Delta \cdots
\end{aligned}
$$

in which $\Delta(\mathrm{km})$ is the epicentral distance. Eqs. $13(\mathrm{a})$ and $13(\mathrm{c})$ were computed with 316 records of 78 earthquakes observed throughout Japan. Eq. 13(b) was derived using 75 records of 16 earthquakes that were selected evenly from magnitude 5.8 through 8.5 . Eq. 13 (c) was computed by imposing the constraint that the coefficient of the second term $\left(\log _{10} D\right)$ be unity to the same data set with Eq. 13(a). Eq. 13(c) is the famous Tsuboi's formula that is the basis of the JMA magnitude scale. The standard errors of estimate of Eqs. 13 are about 0.33. The regression coefficients of Eq. 12 are similar to those of Eqs. 13 (a) and 13 (b). No significant bias is observed in our data set although they include only 20 earthquakes.

The coefficient of determination of 0.87 of Eq. 11 is significantly higher than 0.83 in Eq. 12 . The standard errors of estimate of Eq. $11(0.10)$ is the lowest of Eqs. 11 through 13. It can be concluded that the proposed measurement Eq. 11 is based on an unbiased data set in Japan and has a better resolution than Tsuboi's formula.

The proposed method can be used to measure the magnitude of earthquakes from various sources. A direct physical interpretation of the frictioncontrolled SDOF system is a block on a rough inclined plane. A simple instrument can be fabricated that resembles this system to measure slip displacement. In Fig. 5 is sketched such an instrument. A set of sliding blocks are put on rough planes with various inclinations. The critical acceleration of each block is set to, for example, $25,50,100,150,200$ gals respectively so as to

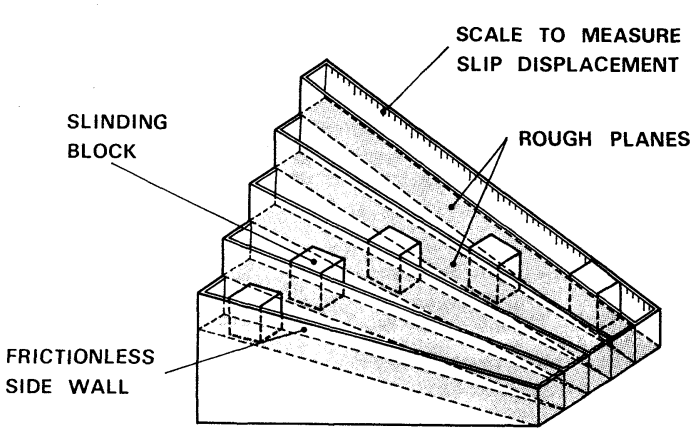

Fig. 5 A simple instrument to measure magnitude. measure finite slip displacements of coming earthquakes. Although it determines whether or not the block slides, the static friction coefficient has been found to have little contribution to the amount of slip displacement on condition that slippage occurs (Igarashi et al. 1985). Therefore, sliding blocks with a different dynamic friction coefficient from the static one can also be employed in this instrument if their critical accelerations are computed from the dynamic friction angle. From previous simulations using a total of 192 strong motion records (Igarashi 1986, Igarashi and Hakuno 1987), it has been found that ship displacements do not change very much when the sign of the critical acceleration is altered or the rough plane is oriented in the opposite direction. Hence, one instrument may be sufficient to one direction. The mass-on-rough plane is the first order approximation model for the slip displacement observed in earth dams, slopes, and structures on direct foundations. One could use field data of the slip displacement of such structures to compute expected magnitudes with Eq. 11.

The slip displacement can be regarded as an index of structural damage due to earthquakes. A considerable amount of seismic energy may be dissipated in the form of slip displacement in various parts of a structure due to a strong ground motion. In this context the friction-controlled SDOF system can be another candidate that measures a global effect of seismic waves on structures. Interestingly an early way to measure the intensity of earthquakes was to observe the movement of objects resting on a shelf. 


\section{SUMMARY AND CONCLUSIONS}

A method to measure the magnitude of earthquakes based on the slip displacement due to ground motions was proposed. This procedure was found to give the magnitude with a low standard error. The proposed method can be used to measure the magnitude of earthquakes from various sources observed at a station, e. g. , accelerograms, movement of a block resting on an inclined plane, and sliding in earth structures.

\section{REFERENCES}

1) Richter, C.F : An Instrumental Earthquake Scale, Bulletin of Seismological Society of America. 25. 1-32, 1935.

2) Richter, C. F : Elementary Seismology, W. H. Freeman, San Francisco, 1958.

3) Gutenberg and Richter: Seismicity of the Earth and Associated Phenomena, Princeton Univ. Press, Princeton, 1949.

4) Kanamori and Jennings: Determination of the Local Magnitude, $M_{L}$, From Strong Motion Accelerograms, Bulletin of Seismological Society of America. 68-2, 1978.

5) California Institute of Technology : Analysis of Strong Motion Earthquake Accelerograms, EERL-72-100, 1972.

6) Gutenberg, B. : Magnitude determination for larger Kern County shocks, 1952 : effects of station azimuth and calculation methods, in Earthquakes in Kern County, California, O. P. Jenkins and G. B. Oakeshott, Editors, Division of Mines, Department of Natural Resources, State of California, San Francisco, 171-175, 1955.

7) Boore, D. M., Joyner, W. B., Oliver, A. A. III and Page, R. A. : Peak Acceleration, Velocity, and Displacement From Strong-Motion Records, Bulletin of Seismological Society of America, Vol.70, No. 1. pp. 305 321, February 1980.

8) Tsuboi, C. : Determination of the Gutenberg-Richter's Magnitude of Earthquakes occurring in and near Japan, Earthquakes, Vol. 2, 7, 1954.

9) Newmark, N. M. : Effects of Earthquakes on Dams and Embankments, Geotechnique, Vol. 15, No. 2, pp. 139 160, Jan., 1965.

10) Sarma, S. K. : Seismic Stability of Earth Dams and Embankments, Geotechnique 25, No. 4, pp. 743 761, 1975.

11) Seed, H. B. : Considerations in the Earthquake-Resistant Design of Earth and Rockfill Dams, Geotechnique 29, No. 3, pp. 215 263, 1979.

12) Richards, R. J. and Elms, D. : Seismic Behavior of Gravity Retaining Walls, Journal of the Geotechnical Engineering Division ASCE, Vol. 105, No. GT 4, pp. 449 464, 1979.

13) Whitman and Liao: Seismic Design of Gravity Retaining Walls, Miscellaneous paper GL-95-1, M. I. T., January, 1985.

14) Igarashi, S., Kajizuka, K. and Hakuno, M. : Statistical Prediction of Rigid-Body-Slip by Earthquake Excitation, Proc. JSCE, No. 536/ I -3, 1985.

15) Igarashi, S. : Statistical Prediction of Slip Displacement Due to Earthquakes, S. M. Thesis, M. I. T., Jan., 1986.

16) Igarashi and Hakuno: The Response of Mass-on-Rough-Plane Model Due to Earthquakes, Proc. JSCE No. $380 /$ I -7, 1987.

17) Okamoto : Earthquake Resistant Engineering, Ohm, Tokyo, 1971.

18) National Oceanic and Atmospheric Administration: Strong Motion Data from Japanese Earthquakes, Report SE $29,1981$.

19) Tsuboi : On the Magnitudes of Earthquakes, Earthquakes, Vol. 10, No. 7, 1957.

(Received August 8 1986) 